\title{
Uma visão antropológica do Direito a partir de Teilhard de Chardin*
}

\author{
Hildegard Taggesell Giostri**
}

Sumário: 1. Apresentação; 2. O Início; 3. Ver; 4. A Matéria Elementar; 5. A Diversidade na Unidade; 6. O Paradoxo Humano; 7. A Evolução da Consciência; 8. A Metamorfose Neolítica; 9. Conclusão; 10. Referências Bibliográficas.

\section{Apresentação}

Ler Teilhard de Chardin é uma aventura.

Interpretá-lo, um desafio.

Este trabalho baseia-se, essencialmente, no produto da leitura e análise de sua obra O Fenômeno Humano, finalizada em 1948, mas que pode ser considerada tão atual como se fora escrita nos dias de hoje.

Da leitura deveríamos construir uma visão antropológica do Direito, ainda que, em parte alguma do citado livro, este tema tenha sido abordado especificamente.

É, no entanto, a obra de Teilhard de Chardin tão abrangente que beber da sua seara é mitigar a sede de qualquer tipo de dúvida e de qualquer perquirição. Era o seu conhecimento de tal maneira enciclopédico que, em algum lugar de sua obra, encontraremos sempre uma resposta, uma informação precisa, uma indicação para o embasamento de qualquer tipo de pesquisa filosófica.

Para o próprio autor, o livro em análise não deveria ser lido como uma obra metafísica, muito menos ainda como uma espécie de ensaio teológico, mas, única e exclusivamente, como uma dissertação científica,

* Monografia apresentada à disciplina de Teoria Geral do Direito, do Curso de Mestrado em

Direito, da Universidade Federal do Paraná, sob orientação do Prof. Dr. Luis Fernando Coelho.

** Mestra em Direito das Relações Sociais pela Universidade Federal do Paraná. Advogada. 
uma introdução a uma explicação do mundo, estabelecendo em volta do Homem, este fenômeno escolhido como centro, uma ordem coerente entre conseqüentes e antecedentes.

Antes de adentrarmos propriamente no tema da presente monografia, algumas referências à pessoa do autor supracitado se fazem necessárias.

Pierre Teilhard de Chardin nasceu em França, em primeiro de maio de 1881, e faleceu na cidade de Nova York em dez de abril de 1955.

Por sua inteligência clara e privilegiada desde cedo distinguiu-se de seus pares, e, na idade adulta foi paleontólogo, filósofo e teólogo.

Mentes como a sua podem ser consideradas como verdadeiros presentes para a Humanidade, que de tempos em tempos é premiada com um avatar para que a escuridão não se alastre demasiadamente; assim, o nosso caminhar fica, de espaços em espaços, enriquecido e iluminado por aqueles seres especiais.

\section{Assim foi Pierre Teilhard de Chardin.}

Como este trabalho é baseado, quase na sua íntegra, na obra $\mathbf{O}$ Fenômeno Humano, vários trechos da mesma serão citados no transcorrer da monografia; por uma questão de didática, e para não ficar monotonamente repetitivo citar a mesma bibliografia em nota de rodapé, optamos por, no desenvolvimento do texto, a cada vez que precisarmos recorrer a uma frase ou a um parágrafo do autor, os mesmos aparecerão em negrito, tendo ao seu final a indicação da página de onde foram extraídos.

\section{O Início}

No que se refere ao nascimento do Universo, a corrente dominante do pensamento científico é unânime em afirmar (até prova em contrário), que o mesmo se originou da imensa explosão de uma nebulosa gigantesca, explosão esta que teria ocorrido há quinze bilhões de anos.

Do agrupamento e ordenação daquele pó cósmico teve início a Vida nas suas plúrimas facetas: a princípio representada pelos átomos, depois pelas micro e macro moléculas e, por fim, pelas células. 
Através uma evolução lenta, mas progressiva, construiu-se este todo que está, não só ao nosso redor mas no nosso interior, e do qual fazemos parte integrante e interagente.

Para entender, neste habitat complexo, o Homem, centro pulsátil, eixo e flexa da evolução (p.11), é necessário ver, ver para conhecer e não perecer (p.06).

\section{Ver}

Por que procurar ver? E porque fixar especialmente o nosso olhar sobre o objeto humano?

Poder-se-ia dizer que toda a vida consiste em ver, - se não finalmente, pelo menos essencialmente -. Ver mais é unir-se mais. (P.06).

A penetração do olhar, no entanto, não é física: é mental e é do espírito; é o fruto do conhecimento e do amadurecimento, resultante única das experiências acumuladas do aqui e do agora somadas às transcendentais (o estudo da memória genética começa a apontar possíveis caminhos para esta última).

Centro de perspectiva, o Homem é ao mesmo tempo centro de construção do Universo. Tanto por conveniência como por necessidade, é pois a ele que, finalmente, toda a ciência tem que ser referida. (P.07).

Se, verdadeiramente, ver é ser mais, olhemos o Homem e viveremos mais.(P.07).

O ser humano é um laboratório em si mesmo. Cada indivíduo é único, seja nas suas análises ou nas suas reações. Vivenciar as nossas experiências e observar as alheias é participar de um universo de situações e soluções diversas. No desafio maior que é viver, é ser sujeito e objeto ao mesmo tempo, aliando-se e transformando-se mutuamente através o conhecimento de si mesmo, de seu semelhante e de seu habitat.

E, no entanto, muitas vezes nada há tão difícil de perceber como o que deveria saltar-nos aos olhos. (P.07).

Até que ponto ir e que profundidade deve ter o nosso olhar para que captemos o sentido real de todos os fenômenos que nos rodeiam, já que o Homem seria o fenômeno maior e central (p.08) de todo os cosmos? 
Se devemos ver para conhecer e não perecer, qual a amplitude ideal e suficiente deste "olhar"? Até que ponto o sentido da visão física deveria ser ampliado para um "visão metafísica"?

Para Teilhard de Chardin, ao Homem para descobrir totalmente o Homem seria necessária toda uma série de "sentidos", cuja aquisição gradual abrangeria e ritmaria a própria história das lutas do Espírito. (P.08).

Esses sentidos, numa abordagem genérica, poderiam ser apontados da seguinte maneira:

Sentido de imensidade espacial, tanto comprimido e no espacejado quanto no indefinido.

Sentido de profundidade ao longo das séries ilimitadas dos acontecimentos gravitacionais.

Sentido do número da multidão alucinante de elementos materiais ou vivos que participam da mínima transformação que ocorre no Universo.

Sentido da proporção que há entre os pequenos grãos de areia da praia e a imensidão de uma galáxia.

Sentido da qualidade, para poder distinguir na natureza a perfeição na dinâmica do crescimento.

Sentido do movimento, para perceber a agitação que há na lentidão daquilo que se mostra repetitivo.

Desprovido total ou parcialmente da profundidade desses sentidos, o Homem continuaria a ser um objeto errático num mundo desconjuntado. (P.09).

O Homem não pode ver-se completamente fora da Humanidade; nem a Humanidade fora da vida; nem a vida fora do Universo. (P.09).

É ele um co-partícipe da evolução e não um mero elemento perdido nas oscilações cósmicas. (P.11). Centro, reflexo, refluxo e conseqüência desta evolução.

Não teria sido para tanto que ele foi criado...? 


\section{A Matéria Elementar}

Pluralidade, unidade, energia: as três faces da matéria. (P.16).

Cada face tem as suas características próprias e manifestar-se-ia, conseqüentemente, de maneira diversa, com base na sua heterogeneidade.

A pluralidade se manifesta na incontável atomicidade da vida que se condensa e flutua como um enxame indecifrável. Exprime-se nas gotas de chuva e na areia das praias. Prolonga-se na multidão dos seres vivos e dos astros. $E$ até se decifra nas cinzas dos mortos. (P.16).

A unidade da matéria elementar se manifesta através a sua perfeita identidade de massa e de comportamento, talvez o mais extraordinário que possa assenhorar-se aos nossos olhos: algo os liga mutuamente, os torna solidários. Simplesmente adicionados ou justapostos os átomos não constituem ainda a Matéria. Engloba-os e cimenta-os uma misteriosa identidade contra a qual o nosso espírito embate e é finalmente forçado a ceder. A esfera acima dos centros, envolvendo-os. (P.18).

Cimento de misteriosa identidade..., mas de plúrimos nomes: Energia, Inteligência Cósmica, Deus...

A terceira face da matéria é representada pelo sentido psicológico do espaço (P.19), ou, traduzindo-o, - a energia. É ela um poder de ligação, de interação, valor de constituição também porque o átomo parece enriquecer-se e esgotar-se durante o intercâmbio. (P.19).

Jamais apreendida de fato, no seu estado puro, a Energia representa para a Ciência a forma mais primitiva do Esforço universal. (P.19).

Assim, o cosmos em que o Homem se encontra implicado constitui-se um Sistema, um Totum e um Quantum: um Sistema péla sua multiplicidade, um Totum pela sua unidade e um Quantum pela sua energia. (P.20).

Sistema é o produto de ordenação das partes do Universo.

A matéria, na sua unidade (ou unicidade) nunca se repete, mas forma estruturalmente um todo.

Sendo coextensivo o átomo, o espaço universal representa o domínio da ação comum a todos os átomos, ação esta exteriorizada por sua energiạ. 


\section{A Diversidade na Unidade}

Na unidade da Natureza existem esferas ou escalóes de ordens diferentes, cada um deles caracterizado pela predominância de certos fatores que se tornam imperceptíveis ou insignificantes na esfera ou no escalão vizinho. (P.33).

É essa diversidade na unidade que faz, talvez, a existência ser, ao mesmo tempo, atrativa e enigmática através a pluralidade dos nossos organismos e de nossas construções (mentais e materiais).

E, nesta diversidade, e sob o ângulo puramente experimental, a convivência manifesta-se como uma propriedade cósmica de grandeza variável, submetida a uma transformação global. (P.39).

A matéria e o espírito, ainda que situados em pólos de atuação diferentes, têm na sua essência um "algo" comum que os une, que os cimenta, que os sustenta e é sua força propulsora: a energia.

Daí concluir o autor que, a energia material e a energia espiritual sustentam-se e prolongam-se por meio de qualquer coisa. (P.44).

O nosso arcabouço físico, através de um complicado sistema metabólico, retira dos alimentos e nutrientes que recebe o necessário para seu desenvolvimento e manutenção. Pondera o autor que, para pensar, é preciso comer. Mas, em contrapartida, que variedade de pensamentos pelo mesmo bocado de pão. (P.44).

Assim, saem das mesmas letras de um mesmo alfabeto tanto as palavras mais incoerentes como o mais belo poema, o mais sábio dos pareceres, a mais profunda sabedoria.

De igual maneira, se as necessidades fisiológicas são basicamente as mesmas para todos os seres humanos, o mesmo não se pode afirmar de suas necessidades mentais, intelectuais ou espirituais.

De posse de maior ou menor cabedal de conhecimento, associado ao uso da razão de uma maneira mais apropriada ou menos, observamos como resultante esta gama imensa de seres heterogêneos e complexos. E, situações há que esta heterogeneidade e esta complexidade se aprofundam de uma tal maneira que vêm a tornar difícil o convívio social de grupos, de povos e até mesmo de nações inteiras. 
Em resumo, pode-se dizer que da posse do conhecimento advém todo o resto. Parece ter sido este também o parecer de inúmeros pensadores ao longo dos séculos.

Heráclito dizia que : "com efeito, todas as coisas acontecem segundo o logos". E, complementando, afirmava que o logos era a verdadeira estrutura interna do conhecer que na sua unidade compreendia e articulava a multiplicidade contraditória do seu devir ${ }^{1}$

O logos, ou conhecimento, associado ao uso da razão foi uma dăs determinantes básicas e possivelmente a mais importante delas, na trajetória sociológica do Homem ao longo de sua caminhada na História.

Kant já evocava a imprescindibilidade de submeter ao ajuizamento da razão o seu próprio poder cognicitivo. ${ }^{2}$

E, anteriormente a este autor, já havia John Locke invocado, à sua peculiar maneira e dentro dos pressupostos de seu pensamento, a radicalidade e o caráter derradeiro do exame racional: "Quando Deus faz o profeta não desfaz o homem (...). A razão tem de ser o nosso último juiz e o guia em tudo (...) temos de consultá-la. ${ }^{3}$

Conclui-se, pois, que a temática da ação, no quadro antropológico, não abdica da atribuição de um papel central dado à racionalidade.

\section{O Paradoxo Humano}

De um ponto de vista meramente positivista, o Homem é o mais misterioso e o mais desconcertante dos objetos com que a. Ciência depara. (P.167).

Para Teilhard de Chardin houve, na evolução do Homem, um momento de culminante importância e ao qual ele deu o nome de

1 Heráclito, frag. B 1 DK; Die Fragmente der Vorsokratiker, ed. Hermam Diels e Walther Kranz, Berlin, Weidmann, 1956, vol. I, p. 150. Citado por José Barata-Moura. A Realização da Razão, um programa hegeliano? Editorial Caminho SA, Lisboa, 1990. P. 25.

2 Cf. I. Kant. Kritik der reinem vernunft, Riga, Hartknoch, 1781. Citado por Barata-Moura, opus cit., p. 28.

3 John Locke. An Essay Concerning Human Understanding, IV, 19, 14; ed. Alexander Cámpbell Fraser. Ney York, Dover Publications, 1959, vol. II, p. 438. Citado por Barata-Moura, opus cit., p. 28.

Revista da Faculdade de Direito da UFPR, Curitiba, a. 29, n. 29, 1996, p. 175-188 
hominização, querendo referir-se à transição do uso apenas do instinto para o uso da reflexão.

O ser reflexivo, precisamente em virtude de sua inflexão sobre si mesmo, torna-se de repente suscetível de se desenvolver numa esfera nova. Na verdade é outro mundo que nasce. Abstração, lógica, opções e invenções ponderadas, matemática, arte, percepção calculada do espaço e da duração, ansiedades e sonhos do amor... Todas estas atividades da vida interior nada mais são que a efervescência do centro recém-formado que explode sobre si mesmo. (Pp. 169-170).

Assim, após uma evolução lenta, porém progressiva, o Homem saído de sua fase meramente instintiva passa a ter a posse da inteligência e, com ela, vem a reflexão. Todo o seu comportamento e toda a sua vida de reflexão começam a mudar a partir daí.

A posse de inteligência representa para o Homem um avanço radical em relação a toda a Vida antes dele. (P. 170).

Analisando o psiquismo dos animais, Teilhard de Chardin ensina que para os Escolásticos da antiga Escola, o instinto é uma espécie de subinteligência homogênia e fixada, que assinala um dos estágios ontológicos e lógicos através dos quais, no Universo, o ser se degrada, se irisa, desde o puro Espírito até a pura Materialidade. (P. 171).

Para o cartesiano, o animal não seria mais que um autômato porque desprovido de pensamento, enquanto que para os biólogos nada separaria nitidamente instinto e pensamento, ambos reflexos diretos dos determinismos da matéria.

Para Teilhard de Chardin o instinto traduziria o próprio fenômeno vital e representaria, como conseqüência, uma grande variável. Em razão disto, seria mais fácil compreender o porquê da diversidade dos comportamentos animais.

Desde que a Evolução é transformação primariamente psíquica não há um instinto na Natureza, mas uma multidão de formas de instinto, cada uma das quais corresponde a uma solução particular do problema da Vida. O psiquismo de um inseto não é (e já não pode ser) o de um vertebrado - nem o instinto de um esquilo o de um gato ou de um elefante: e isto, devido, precisamente, à posição de cada um na Árvore da Vida. 
Por isso mesmo, nessa variedade, começamos a ver salientar-se definitivamente um relevo, desenhar-se uma gradação.

Se o instinto é grandeza variável, os instintos não podem ser apenas diversos: eles constituem, na sua complexidade um sistema crescente - figuram, no seu conjunto, uma espécie de leque onde os termos superiores, em cada nervura, são reconhecíveis por um raio maior de opção, apoiado num centro mais bem definido de coordenação e consciência.

E é exatamente o que observamos. O psiquismo de um cão, diga-se o que se disser, é positivamente superior ao de uma toupeira ou de um peixe.

Deste ponto de vista, poder-se-ia dizer que qualquer forma de instinto tende a tornar-se "inteligência" à sua maneira, mas que só na linha humana (por razões extrínsecas ou intrínsecas), esta operação teve êxito completo. 0 Homem representaria, pois, mas chegada já ao estado reflexivo, uma das inúmeras modalidades de consciência ensaiadas pela vida no mundo animal. Outros tantos mundos psíquicos há nos quais nos é, na verdade, difícil penetrar, não só porque o conhecimento é neles mais confuso, mas também porque este funciona neles de maneira diferente do que se passa em nós. (P. 172-173).

Dentro de uma mesma caminhada evolutiva houve um momento então, em que o Homem distanciou-se, diversificou-se das demais formas que até aquele momento lhe eram de alguma maneira similares. Pela posse da inteligência houve não só simples mudança de grau, - mas mudança de natureza -, que resulta de uma mudança de estado. (P.170).

Para que a visualização desta mudança de estado, - do ser instintivo para o ser reflexivo - se torne mais facilmente compreensível, Teilhard de Chardin assim se expressa:

Quando a água, sob pressão normal, atinge 100 graus, se continuarmos a aquecê-la, o primeiro acontecimento que se segue - sem mudança de temperatura - é a tumultuosa expansão das moléculas libertadas e vaporizadas.

Quando, ao longo do eixo ascendente de um cone, as secções se sucedem, com uma área constantemente decrescente, chega o momento em que, com mais uma deslocação infinitesimal, a superfície se 
esvanece, tornando-se um ponto. Assim, graças a estas vagas comparações, podemos imaginar, no seu mecanismo, o passo crítico da Reflexão. (P.173).

Não mais o ser aprisionado ao instinto puramente animal, no desempenho único da satisfação de suas necessidades fisiológicas, mas o ser agora apto a reiniciar o vôo que o arrancaria para sempre do patamar de igualdade com os outros animais: o vôo para liberdade de ser o Homem.

A passagem à Reflexão é verdadeiramente uma transformação crítica, uma mutação de zero para tudo. (P.177).

Deu-se, portanto a grande transformação: após o grão de Matéria, após o grão de Vida, eis o grão de Pensamento enfim constituído. (P.180).

\section{A Evolução da Consciência}

Munido o novo ser de inteligência e, através do pensamento tendo atingido a Reflexão, as experiências acumuladas começaram a ser gradualmente arquivadas, aproveitadas e manipuladas de acordo com as novas situações que se iam criando naquele mundo novo, produto direto de uma mente também nova.

Essas mudanças, tanto internas como externas, podem ser observadas ao nosso redor também hoje, ou a qualquer momento que a queiramos ver, pois são elas o produto do conhecimento acumulado ao longo dos séculos, a partir daquele momento mágico, quando o Homem pode dispor da tríade Inteligência - Pensamento - Reflexão.

Internamente, podemos observar, como exemplo, que a mente da criança não a mesma da de um adulto, e, que para chegar a tanto percebemos que de ano para ano desenvolve-se a centelha da Reflexão. (P. 185).

Externamente, todos temos também consciência, pelo menos de uma maneira confusa de que algo muda na nossa atmosfera, no decurso da História. (P. 185).

Conclui o autor que sob o esforço livre e engenhoso das inteligências que se sucedem é evidente que algo se acumula irreversivelmente e se transmite pelo menos coletivamente, por educação, através das idades. 
Ora, este algo, construção de matéria ou construção de beleza, sistemas de pensamentos ou sistemas de ação, acaba sempre por se traduzir em aumento de consciência - sendo a consciência por sua vez, como agora o sabemos, nada menos que a substância e o sangue da vida em evolução. (P.186).

O Homem, alfa e ômega da criação, centro, reflexo e ref̣luxo do Universo é, pois, um ser em evolução e, por conseguinte, em constante mutação. Esta mutação ocorre, basicamente, devido à sua acomodação histórico-cultural e ideológica: é a resultante da efervescência das sua múltiplas experiências que, após vivenciadas, o jogam, sucessiva e continuadamente, para novos horizontes.

Em um texto datado de 1840, Arnold Ruge chegara igualmente a esta formulação, assim se expressando:“

"Não há nenhum poeta absoluto ou um valor absoluto, tampouco há uma religião absoluta ou um saber absoluto e consciência (absoluta) do divino; alcançamos o absoluto apenas na História (...). A forma da religião não está perfeita em Cristo, a da poesia não o está em Goethe, a da filosofia não o está em Hegel. Todos eles são tão pouco o fim do espírito que, antes, a sua maior honra está em terem sido o começo de um novo desenvolvimento". 4

Fruto, pois, de sua posse da inteligência, do pensamento, da reflexão, evoluindo para a consciência, o Homem, este fenômeno, é a somatória única da inteligência, do pensamento, da reflexão e das consciências, milhares delas, que lhe até os dias de hoje.

Possivelmente era a isto que Telhard de Chardin se referia quando escreveu esta frase lapidar: o Homem não progride senão elaborando lentamente, através das idades, a essência e a totalidade de um Universo depositado em si próprio. (P. 188).

\section{A Metamorfose Neolítica}

No período neolítico, considerado decisivo para o desencadeamento da socialização, e estando já o Homem de posse da reflexão, um feixe de

4 A. Ruge. Zur Kritik des gegenwärtigen Staats-und Völkerrechts. Ed. Heinz e Ingrid Pepperle. Leipzig, Reclam, 1985, p. 154. Citado por Barata-Moura, opus cit., p. 20.

Revista da Faculdade de Direito da UFPR, Curitiba, a. 29, n. 29, 1996, p. 175-188 
fatores parcialmente independentes parece ter confluído misteriosamente para sustentar e favorecer o avanço da hominização.

Hominização, conforme já citado anteriormente, é, para Teilhard de Chardin, antes de tudo, o salto individual, instantâneo do instinto para o pensamento. (P. 188).

Com base nas informações e deduções que dispomos hoje, tentemos ver mais claramente o que se passou com nosso ancestral na fase neolítica.

Antes de mais, os progressos incessantes da multiplicação; um agrupamento maior de indivíduos queria também significar maior condição de proteção e, portanto, maior segurança. Porém, com o rápido acréscimo do número de habitantes, mais exíguo se torna o terreno livre. Os grupos entrechocam-se. Como conseqüência diminui a amplitude das deslocações, impondo-se, a partir daí, o problema de obter o melhor partido possível de domínios cada vez mais limitados.

Deve ter sido, podemos imaginar, da necessidade de uma solução para tal problema que surgiu a idéia de conservar e de reproduzir no mesmo lugar o que anteriormente era preciso buscar ou perseguir ao longe.

A criação de animais e a cultura de plantas são as mais novas conquistas daquele ser em crescimento: o novo Homem é agora pastor e agricultor: não mais a coleta, mas a colheita; não mais o nomadismo como forma de vida, mas apenas como uma prática opcional, pois ele já tem meios de fixar-se a um solo escolhido e ali produzir e sobreviver com sua prole.

E, é exatamente esse momento da evolução do Homem e do desenvolvimento do seu trabalho que podemos apontar como sendo do PARTO ANTROPOLÓGICO DO DIREITO, fruto único da necessidade de contornar os problemas sociais advindos da convivência dos diversos agrupamentos humanos que começavam a povoar a Terra.

Sobre esse momento histórico assim se expressa Teilhard de Chardin: Em primeiro lugar, nas aglomerações em vias de crescimento aparece a complexidade dos direitos e dos deveres, obrigando a imaginar todas as espécies de estruturas comunitárias e de jurisprudências cujos vestígios persistem sob nossos olhos, à sombra das grandes civilizações, entre as populações menos progressivas da Terra. Socialmente, em matéria de propriedade, de moral, de 
casamento, pode muito bem dizer-se que tudo foi experimentado. (P. 218).

Os vestígios de estruturas comunitárias com suas jurisprudências que ainda hoje se encontram em cantões afastados e longínquos são produtos de etnias que se conservaram à margem da evolução do progresso social e material, permanecendo estagnadas no tempo, contrariando assim a ânsia propulsora dos demais membros de sua espécie.

São, no entanto, em termos de sociedades comunitárias e de direito, rica fonte de pesquisa e de amostragem para uma melhor compreensão do caminho longo, árduo e tortuoso que foi percorrido até chegar ao que hoje alcançamos.

Este tipo de análise e de estudo é, não só importante como necessário, e, bem apontou Julian Huxley: "É o homem a descobrir que ele não é mais do que a Evolução que se tornou consciente de si mesma".

E Teilhard de Chardin diria: o espírito de pesquisa e de conquista é a alma permanente da Evolução. (P.241).

Assim, com o passar dos séculos, desta evolução derivou uma série de novas propostas de vida e, de uma delas havia necessariamente de originar-se o Direito para balisar as diretrizes da vida social e comunitária das embrionárias civilizações.

Se a História é a história do Homem ao longo de sưa imensa trajetória sobre a face da Terra, o Direito é a história das aspirações e legitimações deste mesmo Homem ao longo de sua caminhada pela História.

\section{Conclusão}

Analisando em conjunto os prováveis fatos ocorridos há quinze bilhões de anos e suas conseqüências, não há como não nos maravilharmos com a complexidade da estrutura desta resultante fenomênica chamada Homem.

Pó cósmico, produto de uma explosão monumental. Depois átomo, molécula, micro e macromolécula, e, daí, célula.

5 Julian Huxley, citado por Teilhard de Chardin. O Fenômeno Humano. Livraria Tavares Martins. Porto, Portugal, 1970. P. 237.

Revista da Faculdade de Direito da UFPR, Curitiba, a. 29, n. 29, 1996, p. 175-188 
No interior do ser já formado - instinto.

Depois, o salto para o pensamento.

Posse da inteligência, reflexão, consciência, racionalidade. Expansão do conhecimento através a experiência.

Ampliação das necessidadies; percepção primeira da existência de direitos e deveres - a vida em evolução - e, decorrência natural dessa evolução - o Direito.

Flexa ascendente da grande síntese biológica, vai o Homem encetar a longa caminhada em direção ao seu devir.

Somatória fenomênica de elementos químicos, físicos e biológicos, aliados a uma inteligência capaz de racionalizar, está ele apto a direcionar sua vida no sentido da paz, da harmonia, da felicidade, dando a cada um o que é de si e respeitando direitos enquanto cumpre deveres.

"Só o humano é o verdadeiro e real, pois só o humano é o racional; só o Homem é a medida da razão."

FEUERBACH

\section{Referências Bibliográficas}

TEILHARD DE CHARDIN, Pierre. O Fenômeno Humano. Livraria Tavares Martins: Porto, Portugal - 1970.

BARATA-MOURA, José. A realização da Razão, um programa hegeliano? Editorial Caminho SA: Lisboa, Portugal - 1990. 